\title{
AN INSULATION THICKNESS OPTIMIZATION METHODOLOGY FOR SCHOOL BUILDINGS REHABILITATION COMBINING ARTIFICIAL NEURAL NETWORKS AND LIFE CYCLE COST
}

\author{
Ricardo M. S. F. ALMEIDA ${ }^{\mathrm{a}, \mathrm{b}}$, Vasco Peixoto DE FREITAS ${ }^{\mathrm{b}}$ \\ a Polytechnic Institute of Viseu, School of Technology and Management, Department of Civil Engineering, \\ Campus Politécnico de Repeses, 3504-510 Viseu, Portugal \\ ${ }^{b}$ University of Porto, Faculty of Engineering, Department of Civil Engineering, Laboratory of Building Physics, \\ Rua Dr. Roberto Frias s/n, 4200-465 Porto, Portugal
}

Received 28 Nov 2013; accepted 10 Apr 2014

\begin{abstract}
The energy efficiency of buildings, including public buildings, is a major concern for all European governments, since they are responsible for a large share of the total energy bill of the states. School buildings play an important role in these costs. The best strategy for reversing this scenario includes efforts on buildings retrofit, seeking to optimize their energy efficiency and indoor environmental quality. However, in the unfavourable economic climate we are experiencing, which requires great prudence when it comes to public investment, special attention should be given to this multi-objective optimization process. In this research, a methodology to optimize the insulation thickness of the external walls and roof on school buildings retrofit is proposed. The procedure includes the optimization of the building performance considering the following objectives: the minimization of the annual heating load; the minimization of the discomfort in the classrooms due to overheating; and the minimization of the life cycle cost of retrofitting external walls and roof. This methodology was applied to two Portuguese school buildings.
\end{abstract}

Keywords: artificial neural networks, life cycle cost, optimization, school buildings retrofit, building simulation, insulation thickness.

\section{Introduction}

The energy efficiency of buildings, including public buildings, is a major concern for all European governments (Communities 2003, 2010). In Portugal, public buildings are responsible for more than $50 \%$ of the total energy bill of the state and school buildings play an important role in these costs. The best strategy to reverse this scenario includes efforts on the rehabilitation of these buildings, improving their energy efficiency, without sacrificing the indoor environmental quality. These interventions must be carefully prepared and the technical decisions must be scientifically supported to guarantee the economic sustainability of the buildings, often neglected during the design process. The rehabilitation of a school building should be regarded as a procedure of combining a number of variables and objectives, sometimes conflicting, including energy, indoor environmental quality and costs (initial, operational and maintenance), on a search for an "optimum solution".

The compatibility of conflicting objectives, including economic aspects, in optimization procedures is the subject of interest and attention of numerous researchers from various areas (Diakaki et al. 2008, 2010;
Mateus, Oliveira 2009; Calise et al. 2011; Calise 2012; Kumbaroğlu, Madlener 2012; Ozel 2012; Hamdy et al. 2013). In building rehabilitation, it is often accomplished by the creation of a large number of construction scenarios, which establish the decision space. These scenarios are simulated and evaluated, resulting in a ranking of the solutions (Santamouris et al. 2007; Calise 2010; Ochoa et al. 2012). This method is relatively fast and easy to implement. However, the final solution is restricted to the scenarios that were initially defined. This limitation can be overcome by other approaches, based on more complex numerical methods, where the decision space is extended and optimization procedures based on evolutionary algorithms, such as the genetic algorithms, are employed. These methods, when applied to problems with more than one objective, result in a set of optimal solutions, each of which represents a particular level of compromise between the objectives. To establish a criterion for the rejection of feasible solutions during the optimization process, these methods use the concept of dominance and the final set of optimum solutions is called the Pareto front. The optimal Pareto solutions are situated

Corresponding author: Ricardo M. S. F. Almeida

E-mail: ralmeida@estv.ipv.pt 
in a region where it is impossible to improve any of the objectives, without degrading at least one of the other objectives (Deb 2001; Konak et al. 2006).

Typically, these methods are applied in building energy optimization together with computer simulation software, such as EnergyPlus, TRNSYS or ESP-r, that are responsible for evaluating the effect of a particular solution (rehabilitation scenario) on each of the established objectives, that should be quantitatively described by mathematical functions.

One of the first applications of genetic algorithms in the optimization of buildings energy consumption was made by Wright et al. (2002) in the identification of the optimum pay-off characteristic between the energy cost of a building and the occupants' thermal discomfort. Magnier and Haghighat (2010) used a popular multi-objective genetic algorithm (NSGA-II) for the optimization of thermal comfort and energy consumption in a residential house. Chantrelle et al. (2011) developed a multicriteria tool for the optimization of renovation operations.

The main limitation of these methodologies is the large number of computer simulations required by the genetic algorithm, making it almost impractical when applied directly to the thermal and energy computer simulation of complex models over extended periods. Several researchers proposed alternatives to overcome this difficulty using statistical methods, such as time-series, Fourier series, regression models and Artificial Neural Networks (ANN) (O’Neill et al. 1991; Dhar et al. 1998; Karatasou et al. 2006; Freire et al. 2008; Catalina et al. 2008). Statistical methods are prediction models that use functions to approximate the solutions and can be used both in continuum and discrete problems. ANN models are based on the central nervous system of the human brain. It is a network of interconnected neurons, which have the capacity for self-learning, when properly trained, and can respond to stimulus (inputs). ANN are already programmed on a Matlab Toolbox (2006), making them easy to use, and they tend to perform better than other statistical methods in this kind of problems due to its ability to model non-linear patterns (Kreider 1991; Kawashima et al. 1995; Tso, Yau 2007; Kumar et al. 2013). ANN were employed in a number of diverse applications. Ben-Nakhi and Mahmood (2004) used ANN to investigate the feasibility of this technology to optimize HVAC thermal energy storage in public and office buildings. Indoor temperature of a residential building was predicted with auto regressive with exogenous input neural networks in a research by Mechaqrane and Zouak (2004). Aydinalp et al. (2004) used an ANN method to model residential energy consumption. Boithias et al. (2012a, b) used genetic algorithms and ANN with regard to two objectives: energy consumption and indoor discomfort. Gossard et al. (2013) presented a method to optimize the equivalent thermophysical properties of the external walls of a dwelling in order to improve its thermal efficiency. The methodology included the use of ANN and the genetic algorithm NSGA-II. In this paper
ANN were employed to approximate the pre-established performance functions that describe the objectives (heating load and overheating).

Another difficulty concerning the application of multi-objective optimization methodologies is related to the final choice of a single solution, since all the solutions belonging to the Pareto front are optimal and, therefore, theoretically, none is better than the other. These difficulties are described in the work of Magnier and Haghighat (2010), Suga et al. (2010) and Chantrelle et al. (2011) and a possibility to overcome them is to employ the weighted sum method. This classical approach to solve a multiobjective optimization problem consists in assigning a weight to each normalized objective function so that the problem is converted to a single objective problem with a scalar objective function (Konak et al. 2006). Despite deficiencies with respect to depicting the Pareto optimal set, the weighted sum method for multi-objective optimization continues to be used extensively not only to provide multiple solution points by varying the weights consistently, but also to provide a single solution point that reflects preferences presumably incorporated in the selection of a single set of weights (Marler, Arora 2010). However, the final solution is highly dependent on the chosen weights.

This paper explores another possibility to obtain a single solution: the use of Life Cycle Cost (LCC) analysis as a final criterion for a unique solution. The use of LCC is common in buildings retrofit optimization. Gustafsson (2000) applied this method for the optimization of insulation measures in existing buildings and Hasan et al. (2008) have used LCC, combined with simulation, on the optimization of the U-values of typical Finnish constructions. Other economic approaches to the optimum thickness of insulation materials can be found in the literature (Ozel 2012, 2013).

In this research, a methodology to optimize the insulation thickness of the external walls and roof on school buildings rehabilitation is proposed. The first part of the paper includes the optimization of the building performance considering two objectives: the minimization of the annual heating load and the minimization of the discomfort in the classrooms due to overheating. From this procedure the Pareto front of optimum solutions was defined. In the second part the LCC of the Pareto solutions was calculated and the minimum value corresponds to the economic optimization of the insulation thickness. Two typical Portuguese school buildings constitute a base case where the opportunities and limitations of the methodology are discussed.

The following sections of this paper are organized as follows: the next section presents the methodology applied; Section 2 contains the description of the case studies; Section 3 presents the multi-objective optimization; the life cycle cost implementation is included in Section 4 and; finally, the main conclusions are exposed.

\section{Methodology}

The main objective of this work is to propose an insulation thickness optimization methodology for school 
buildings rehabilitation, based on criteria of energy efficiency, occupants' thermal comfort and life cycle cost. Therefore, the definition of decision variables (parameters to be optimized) and objective functions is required, in order to start the multi-objective optimization procedure. Two mathematical functions (performance functions), whose calculation implies an annual simulation of the building performance, were created to quantify the objectives. The building models were generated with DesignBuilder and the software chosen for the simulations was EnergyPlus. Since these simulations are time consuming and an optimization procedure requires a large number of data, it was decided to use ANN to approximate the value of the performance functions. The ANN were then optimized, using the NSGA-II genetic algorithm. The result was the Pareto front of optimum solutions. Additionally, the LCC of wall and roof rehabilitation was computed and minimized, in order to achieve the optimum insulation thickness.

\subsection{Decision variables and objective functions}

The selected decision variables are properties of the constructive elements of the building envelope, whose performance is typically improved in a rehabilitation intervention, namely the heat transfer coefficient of external walls $\left(U_{\text {wall }}\right)$, roof $\left(U_{\text {roof }}\right)$ and windows $\left(U_{\text {window }}\right)$ and the total solar energy transmittance of windows $\left(\mathrm{G}_{\text {window }}\right)$. Since building ventilation represents a major contribution for both energy performance and thermal comfort, the air change rate (ACR) was also considered as a decision variable.

Previous studies (Guedes et al. 2009; Almeida, Freitas 2010) have concluded that, in terms of thermal comfort, the Portuguese climate allows the use of natural ventilation systems in schools, combined with a heating system, such as hot water radiators, which guarantee adequate temperatures during the winter season. However, some difficulties might be found related to the indoor air quality and, during summer, overheating could be a problem in some classrooms.

Hence, two performance functions were created. The first is the annual heating load, defined as the necessary energy to guarantee a minimum temperature of $20{ }^{\circ} \mathrm{C}$ inside the classrooms and the second function intends to assess the discomfort in the classrooms due to overheating, by quantifying the time with temperatures above $25^{\circ} \mathrm{C}$, both considering only the theoretical period of occupation (8:30 to 18:00). The functions are obviously dependent on the five decision variables stated before and were computed from the results of the annual simulations of the building, performed with Energy Plus, as defined in Eqns (1) and (2):

$\left\{\begin{array}{l}f_{1}\left(U_{\text {wall }}, U_{\text {roof }}, U_{\text {window }}, G_{\text {window }}, A C R\right)=\frac{\sum_{\text {year }} H . L .}{A} \\ T_{\text {int }} \geq 20^{\circ} \mathrm{C}\end{array} ;\right.$

$$
\left\{\begin{array}{c}
f_{2}\left(U_{\text {wall }}, U_{\text {roof }}, U_{\text {window }}, G_{\text {window }}, A C R\right) \\
=\frac{\sum_{\text {year }}\left(T_{\text {int }}-25\right)}{A} \\
T_{\text {int }}>25^{\circ} \mathrm{C}
\end{array},\right.
$$

where: H.L. - hourly heating load (kWh); $A$ - net floor area of the building $\left(\mathrm{m}^{2}\right) ; T_{\text {int }}$ - hourly average interior temperature $\left({ }^{\circ} \mathrm{C}\right)$. H.L. and $T_{\text {int }}$ are outputs of the simulation.

\subsection{Artificial neural networks}

The main concept of ANN is learning. After the definition of the internal architecture, the ANN starts an iterative self-learning procedure of a function by adjusting the internal weights. This training process requires the definition of input data, and respective outputs, in a sufficient number to cover all the variables space, in order to achieve reliable approximations. After training, the ANN should be validated with a different set of input/output data.

The architecture of the networks employed in this research was of the multi-layer feedforward type with backpropagation, 20 neurons (receives $\mathrm{n}$ inputs plus a bias term, which allows to shift the activation function), 5 inputs $\left(\mathrm{I}_{1}\right.$ to $\left.\mathrm{I}_{5}\right)$ and 1 output (Out), as schematically described in Figure 1. The training algorithm was the Levenberg-Marquardt, with Bayesian regulation. The required training sample was defined using the Latin Hypercube Sampling method, which guarantees an effective distribution of the data over the variables space.

\subsection{Multi-objective optimization}

The most common multi-objective optimization procedures are the evolutionary algorithms, inspired by Darwin's theory of natural selection. These algorithms are based on stochastic approaches and their main advantage is that a large number of solutions (population) is used in each iteration, instead of improving one single solution.

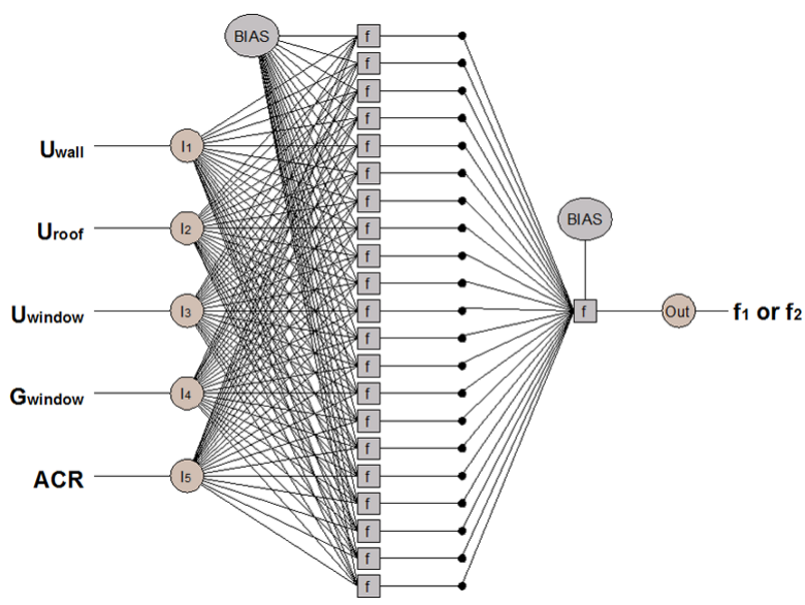

Fig. 1. Artificial neural networks architecture 


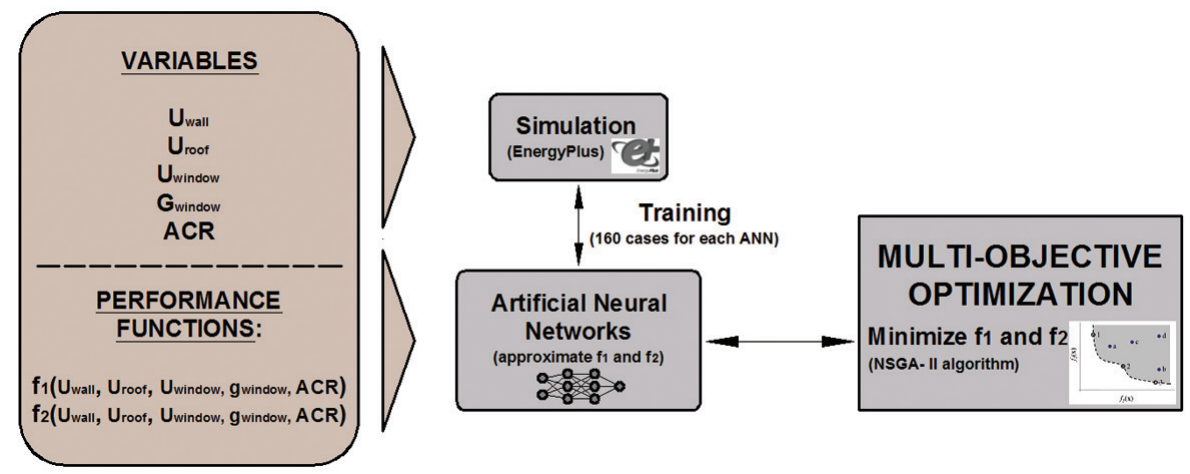

Fig. 2. Multi-objective optimization methodology

Furthermore, in these algorithms, the spreading of the solution front is ensured by internal operators, such as the Crowding Distance. The multi-objective algorithm chosen for this research was the NSGA-II, developed by Deb (2001). Figure 2 schematically describes the proposed multi-objective optimization methodology.

\subsection{Life cycle cost}

LCC is the sum of the present value of investment and operating costs for the building and service systems, including those related to maintenance and replacement, over a specified life span.

In the context of this investigation, the absolute value of the LCC of each retrofitting solution is not required. It can be substituted by the difference $d L C C i$, between the LCC for any case $i$ and that for the reference case. This way, there is no need to include cost data for all components of the building, but only the differences produced by the variation on the insulation thickness between the reference case and any other case. This methodology was proposed and applied by Hasan et al. (2008). Thus, the LCC difference, $d L C C i$, for this situation is:

$$
d L C C_{i}=(d I c)_{i}+(d O c)_{i},
$$

where: $d I c$ - difference in the initial investment cost $(€)$; $d O c$ - difference in the operating cost $(€)$.

The $d L C C i$ was separately computed for wall and roof retrofit.

The difference in the initial investment cost of a retrofit scenario $i$ can be computed from:

$$
(d I c)_{i}=\left[C_{i n s} \times \lambda_{i n s} \times S \times\left(\frac{1}{U_{r e}}-\frac{1}{U_{i n i}}\right)\right]_{i},
$$

where: $C_{i n s}-$ cost of insulation $\left(€ / \mathrm{m}^{3}\right) ; \lambda_{\text {ins }}-$ thermal conductivity of the insulation $(\mathrm{W} /(\mathrm{mK})) ; S$ - area of the constructive element, wall or roof $\left(\mathrm{m}^{2}\right) ; U_{r e}$ - heat transfer coefficient of the retrofitted element $\left(\mathrm{W} /\left(\mathrm{m}^{2} \mathrm{~K}\right)\right) ; U_{i n i}-$ heat transfer coefficient of the element before retrofit $\left(\mathrm{W} /\left(\mathrm{m}^{2} \mathrm{~K}\right)\right)$.

$d O c$ is due to the difference in the annual heating load. $d O c$ calculated to present value, for scenario $i$, is:

$$
(d O c)_{i}=\left[d f \times c_{e} \times\left(H D_{r e}-H D_{i n i}\right)\right]_{i},
$$

where: $d f$ - discount factor which takes into account the effect of inflation and variation of energy price (this way one can use current or constant dollars analysis); $c_{e}$ - energy price $(€ / \mathrm{kWh}) ; H D_{r e}$ - annual heat demand after retrofit $(\mathrm{kWh}) ; H D_{i n i}-$ annual heat demand before retrofit $(\mathrm{kWh})$.

The discount factor, $d f$, is calculated from:

$$
d f=\frac{1-(1+r)^{-n}}{r},
$$

where: $r$ - real interest rate; $n$ - period of analysis (years).

$H D_{r e}$ and $H D_{i n i}$ are the output of the first performance function (Eqn (1)) and can be estimated from the respective ANN.

\section{Case studies}

\subsection{Models}

The methodology was applied to two typical Portuguese school buildings (model A and model B). The building models were created with DesignBuilder and simulated with EnergyPlus. Four types of zones were considered, each with specific metabolic rates, occupation density and schedules:

- Classroom: $95 \mathrm{~W} /$ person; 0.40 person $/ \mathrm{m}^{2}$;

- Circulation: $110 \mathrm{~W} /$ person; 0.60 person $/ \mathrm{m}^{2}$;

- Storage: $110 \mathrm{~W} /$ person; 0.10 person $/ \mathrm{m}^{2}$;

- Toilet: $110 \mathrm{~W} /$ person; 0.60 person $/ \mathrm{m}^{2}$.

The simulations were performed on annual bases, with hourly outputs, and 10 time steps per hour. A summer holiday period of two months (July and August) and a two weeks break at Christmas were considered. Simulations were performed on an Intel Pentium I5 750 (8M Cache, $2.66 \mathrm{GHz}$ ) computer and the time needed for one simulation run by EnergyPlus was 25 minutes for building model $\mathrm{A}$ and 35 minutes for building model $\mathrm{B}$.

The schools original walls and roof have no insulation, the windows are single glazed, there are no heating systems and the ventilation is natural, dependent on the window opening and infiltrations. The values considered in the simulation for the most relevant construction 
elements properties were defined after a complete survey carried out on 20 similar school buildings. Blinds with medium reflectivity slats were considered as shading devices, with operation by solar radiation control with a set point of $120 \mathrm{~W} / \mathrm{m}^{2}$. This way passive measures of protection from solar heat are included in the model. This is a very simple approach to the problem that deserves further investigation. The main difference between the models is the roof $U$ value, which is lower in model B. The air change rate was evaluated experimentally, by tracer gas measurements, considering different envelope scenarios. The simulation models were validated with in situ measurements, as stated in Almeida and Freitas (2010).

The rehabilitation proposal comprises the introduction of insulation in walls and roof, improvement of the windows properties and inclusion of hot water radiators as heating systems. Since the measurements performed in these buildings revealed that, in winter conditions, temperature is below comfort limits, it is considered in this study that the introduction of heating systems is essential and, as so, even when the current performance of the building is referred, we are assuming the inclusion of the hot water radiators.

The study included the analysis in three locations, A, $\mathrm{B}$ and $\mathrm{C}$, each with a climate that is considered characteristic of its region and that together represent the different climatic conditions in Portugal. Were also considered four different predominant orientations for the buildings.

For the five decision variables a range of variation (variables space) was considered as presented in Table 1. The minimum value of the ACR, despite being far from guaranteeing an adequate indoor air quality, was selected

Table 1. Decision variables limits - variables space

\begin{tabular}{lccccc}
\hline & $\begin{array}{c}\mathrm{U}_{\text {wall }} \\
{\left[\mathrm{W} /\left(\mathrm{m}^{2} \mathrm{~K}\right)\right]}\end{array}$ & $\begin{array}{c}\mathrm{U}_{\text {roof }} \\
{\left[\mathrm{W} /\left(\mathrm{m}^{2} \mathrm{~K}\right)\right]}\end{array}$ & $\begin{array}{c}\mathrm{U}_{\text {window }}\left[\mathrm{W} /\left(\mathrm{m}^{2} \mathrm{~K}\right)\right] \\
\text { Maximum }\end{array}$ & $\begin{array}{c}\mathrm{G}_{\text {window }} \\
{[-]}\end{array}$ & $\begin{array}{c}\text { ACR } \\
{\left[\mathrm{h}^{-1}\right]}\end{array}$ \\
\hline Minimum & 0.25 & 3.00 & 6.10 & 0.90 & 5.00 \\
& 0.25 & 1.00 & 0.20 & 0.10 \\
\hline
\end{tabular}

Table 2. ANN $\mathrm{R}^{2}$ for model A given the current conditions of the buildings (Almeida, Freitas 2010). The maximum limits for the exterior walls, roof and windows were defined in accordance with the current characteristics of the school buildings.

\subsection{Artificial neural networks validation}

The calculation of the performance functions implies an annual simulation of the building. Since these simulations are time consuming and the NSGA-II requires a large number of inputs, it was decided to use ANN to approximate the functions. However, the ANN must be properly trained, in order to have an adequate performance. Thus, for each ANN, 150 cases for training and 10 cases for validation were created. The study included 3 locations and 4 orientations, so 1920 annual simulations were necessary for each building model, in order to obtain the input/output data set for the ANN training. A total of 96 ANN (48 for each model) were produced, as schematically illustrated in Figure 3.

To automatize the calculation procedure of the performance functions, a Visual Basic program was developed and employed in the training and validation of the ANN.

The ANN validation accuracy was confirmed with the respective coefficient of determination $R^{2}$ :

$$
R^{2}=1-\frac{\sum_{i=10}^{10}\left(y_{i}-p_{i}\right)^{2}}{\sum_{i=10}^{10}\left(y_{i}-y_{m}\right)^{2}},
$$

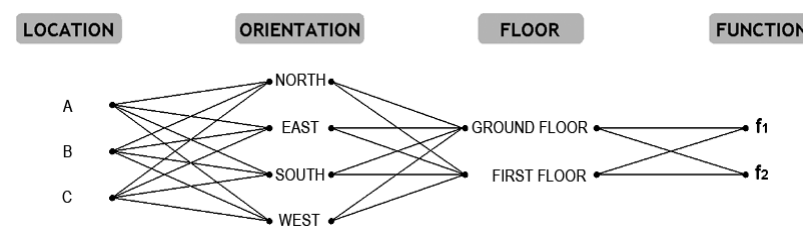

Fig. 3. ANN combinations

\begin{tabular}{|c|c|c|c|c|c|c|c|}
\hline & & \multicolumn{2}{|c|}{ LOCATION A } & \multicolumn{2}{|c|}{ LOCATION B } & \multicolumn{2}{|c|}{ LOCATION C } \\
\hline & & $\mathrm{f}_{1}$ & $\mathrm{f}_{2}$ & $\mathrm{f}_{1}$ & $\mathrm{f}_{2}$ & $\mathrm{f}_{1}$ & $\mathrm{f}_{2}$ \\
\hline \multirow{2}{*}{$\mathrm{N}$} & GF & 0.9990 & 0.9727 & 0.9989 & 0.9800 & 0.9990 & 0.9252 \\
\hline & $1^{\text {st }} \mathrm{F}$ & 0.9976 & 0.9949 & 0.9969 & 0.9832 & 0.9983 & 0.9865 \\
\hline \multirow{2}{*}{$\mathrm{E}$} & GF & 0.9990 & 0.9766 & 0.9989 & 0.9784 & 0.9990 & 0.9045 \\
\hline & $1^{\text {st }} \mathrm{F}$ & 0.9979 & 0.9840 & 0.9969 & 0.9864 & 0.9979 & 0.9899 \\
\hline \multirow{2}{*}{$\mathrm{S}$} & GF & 0.9990 & 0.9323 & 0.9988 & 0.9711 & 0.9990 & 0.9818 \\
\hline & $1^{\text {st }} \mathrm{F}$ & 0.9980 & 0.9871 & 0.9963 & 0.9865 & 0.9978 & 0.9995 \\
\hline \multirow{3}{*}{ W } & GF & 0.9990 & 0.9751 & 0.9988 & 0.9719 & 0.9989 & 0.9868 \\
\hline & $1^{\text {st }} \mathrm{F}$ & 0.9980 & 0.9886 & 0.9966 & 0.9670 & 0.9983 & 0.9962 \\
\hline & & 0.9984 & 0.9764 & 0.9978 & 0.9781 & 0.9985 & 0.9417 \\
\hline \multirow{2}{*}{\multicolumn{2}{|c|}{ MEAN VALUES }} & \multicolumn{2}{|c|}{0.9874} & \multicolumn{2}{|c|}{0.9879} & \multirow{2}{*}{\multicolumn{2}{|c|}{0.9701}} \\
\hline & & & & & & & \\
\hline
\end{tabular}

$\mathrm{N}$ - North; E - East; S - South; W - West; GF - ground-floor; 1st F - first floor. 
Table 3. ANN $\mathrm{R}^{2}$ for model B

\begin{tabular}{|c|c|c|c|c|c|c|c|}
\hline & & \multicolumn{2}{|c|}{ LOCATION A } & \multicolumn{2}{|c|}{ LOCATION B } & \multicolumn{2}{|c|}{ LOCATION C } \\
\hline & & $\mathrm{f}_{1}$ & $\mathrm{f}_{2}$ & $\mathrm{f}_{1}$ & $\mathrm{f}_{2}$ & $\mathrm{f}_{1}$ & $\mathrm{f}_{2}$ \\
\hline \multirow{2}{*}{$\mathrm{N}$} & GF & 0.9953 & 0.9618 & 0.9939 & 0.9756 & 0.9973 & 0.9839 \\
\hline & $1^{\text {st }} \mathrm{F}$ & 0.9959 & 0.9876 & 0.9953 & 0.9839 & 0.9961 & 0.9912 \\
\hline \multirow{2}{*}{ E } & GF & 0.9956 & 0.9444 & 0.9949 & 0.9854 & 0.9971 & 0.9864 \\
\hline & $1^{\mathrm{st}} \mathrm{F}$ & 0.9961 & 0.9767 & 0.9960 & 0.9955 & 0.9964 & 0.9892 \\
\hline \multirow{2}{*}{ S } & GF & 0.9956 & 0.9790 & 0.9952 & 0.9907 & 0.9936 & 0.9899 \\
\hline & $1^{\text {st }} \mathrm{F}$ & 0.9960 & 0.9955 & 0.9943 & 0.9873 & 0.9968 & 0.9937 \\
\hline \multirow{3}{*}{ W } & GF & 0.9955 & 0.9772 & 0.9951 & 0.9823 & 0.9971 & 0.9759 \\
\hline & $1^{\text {st }} \mathrm{F}$ & 0.9954 & 0.9779 & 0.9949 & 0.9822 & 0.9967 & 0.9904 \\
\hline & & 0.9957 & 0.9750 & 0.9949 & 0.9854 & 0.9964 & 0.9876 \\
\hline \multirow{2}{*}{ MEAN VALUES } & & \multicolumn{2}{|c|}{0.9853} & \multicolumn{2}{|c|}{0.9902} & \multicolumn{2}{|c|}{0.9920} \\
\hline & & \multicolumn{6}{|c|}{0.9892} \\
\hline
\end{tabular}

N - North; E - East; S - South; W - West; GF - ground-floor; 1st F - first floor.

where: $R^{2}$ - coefficient of determination; $y_{i}$ - exact value of the function computed from the annual simulation; $p_{i}-$ predicted value of the function computed from the ANN; $y_{m}$ - mean value of the $y_{i}$.

Tables 2 and 3 show the $R^{2}$ results, for models $\mathrm{A}$ and $\mathrm{B}$, respectively. Very accurate approximations were obtained, with overall mean values of 0.9818 and 0.9892 .

\section{Multi-objective optimization}

The first multi-objective optimization procedure was the minimization of the two performance functions, $f_{1}$ (energy) and $\mathrm{f}_{2}$ (overheating), described in Eqns (1) and (2). The evolutionary algorithm, specifically the genetic algorithm NSGA-II, available in a Matlab Toolbox, was employed. The parameters chosen for the optimization were the following:

- Population: 100;

- Selection function: Tournament;

- Reproduction: $80 \%$ crossover and $20 \%$ mutation;

- Crossover function: Intermediate;

- Pareto front population fraction: 1.

The optimization task included the analysis of both school models, considering the three locations and the four possible predominant orientations. Consequently, a large number of outputs (Pareto front) were produced. As an example, Figure 4 shows the Pareto front obtained for the building model A, with east orientation, and for the three locations under study. The point that represents the current performance of the building is also included.

Results revealed that there is a significant improvement potential for all locations and, it was also clear, that it is directly related to the climate: location B is conditioned by function $\mathrm{f}_{2}$, since in this location summer conditions are decisive; location $\mathrm{C}$ is strongly conditioned by function $\mathrm{f}_{1}$, since in this location winter conditions are more severe; location A has the mildest climate.

However, it is evident that the results are highly dependent on the minimum and maximum limits imposed on

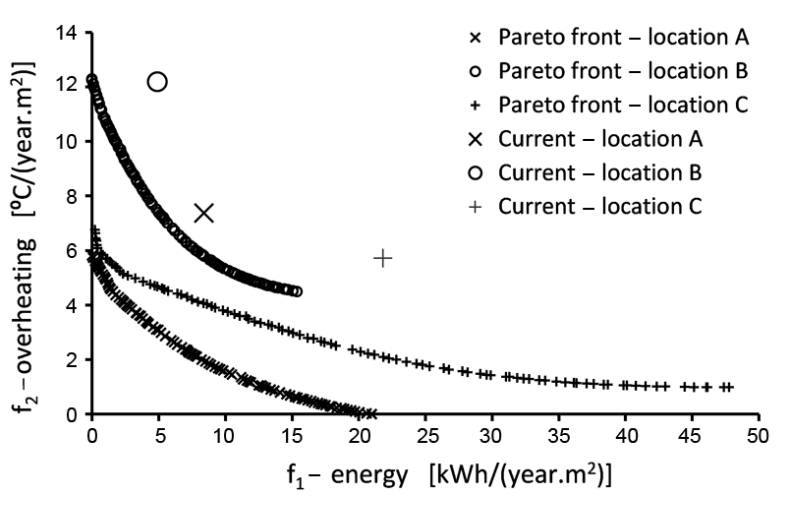

Fig. 4. Multi-objective optimization output

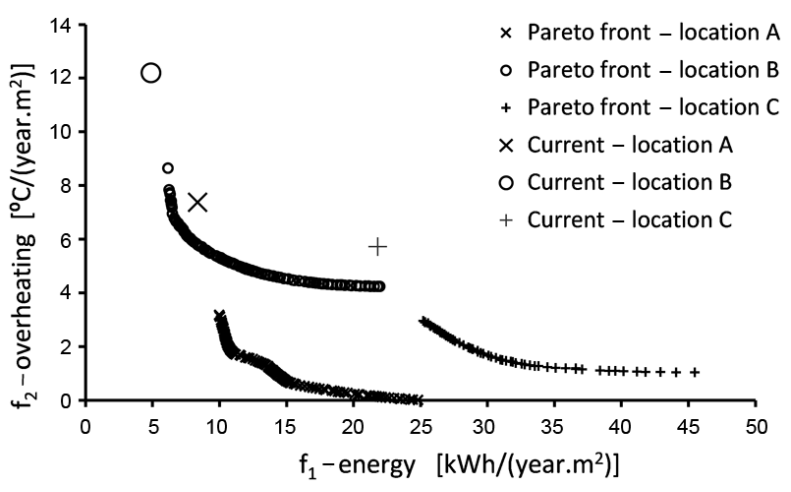

Fig. 5. Multi-objective optimization output

the variables. In fact, most of the optimal solutions correspond to unrealistic constructive scenarios, especially for the ACR, with very low values that cannot be considered valid, since that would lead to inadequate air quality inside classrooms. Therefore, it was decided to proceed to a new multi-objective optimization, establishing a minimum ACR of $1.5 \mathrm{~h}^{-1}$, which, for typical occupation of the classroom, corresponds to $3.125 \mathrm{l} /($ s.person). Figure 5 shows the results of this optimization, for the same scenario.

Results are significantly different from those obtained initially, since Pareto fronts are now less 
dispersed. In fact, the initial variability of the optimum solutions resulted from the possibility of considering low $\mathrm{ACR}$, allowing for constructive scenarios with unrealistic heating energy demands.

Another important feature that arises from the imposition of a minimum ventilation rate is that the solution adopted for the rehabilitation will always lead to an increase in the annual heating load. As described in Almeida and Freitas (2010), current Portuguese school buildings do not provide their users with appropriate indoor air quality conditions, allowing, this way, a minimization of the heating energy demand. In short, the necessary improvement of the indoor air quality will correspond to an increase in the operational cost of the building.

\section{Life cycle cost}

The methodology described in Section 1.4 was implemented for the calculation of the optimum insulation thickness of walls and roofs in school buildings rehabilitation. With this objective, a software tool, written in Excel VBA, was developed. This application allows optimizing the life cycle cost of the insulation, after the definition of the economic scenario and of the period of analysis.

Software computes the LCC of each rehabilitation scenario that belongs to the Pareto front and for the reference case. Then the $d L C C i$ is determined and minimized. The minimum value corresponds to the optimum solution.

To make the application as comprehensive as possible, the user can define all the variables required for the complete characterization of the problem. The input data can be gathered into three groups: initial options, which include model type, location, orientation and air change rate; investment, which includes insulation price and its thermal conductivity; and economic analysis, which includes period of analysis, energy price, real interest rate, inflation and the expected variation on the energy price.

The main objective of this paper is the description of the methodology, rather than the presentation of a particular example. However, an example case of a school building located in Porto (location A), with west orientation, whose constructive characteristics correspond to the simulation model A (Figure 6), was performed in order to illustrate the applicability and capabilities

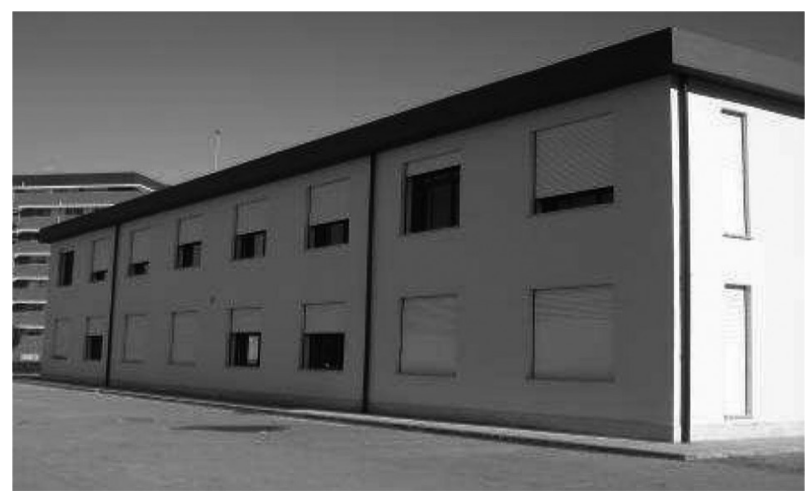

Fig. 6. Example case: school building in Porto (location A)
Table 4. Example case inputs

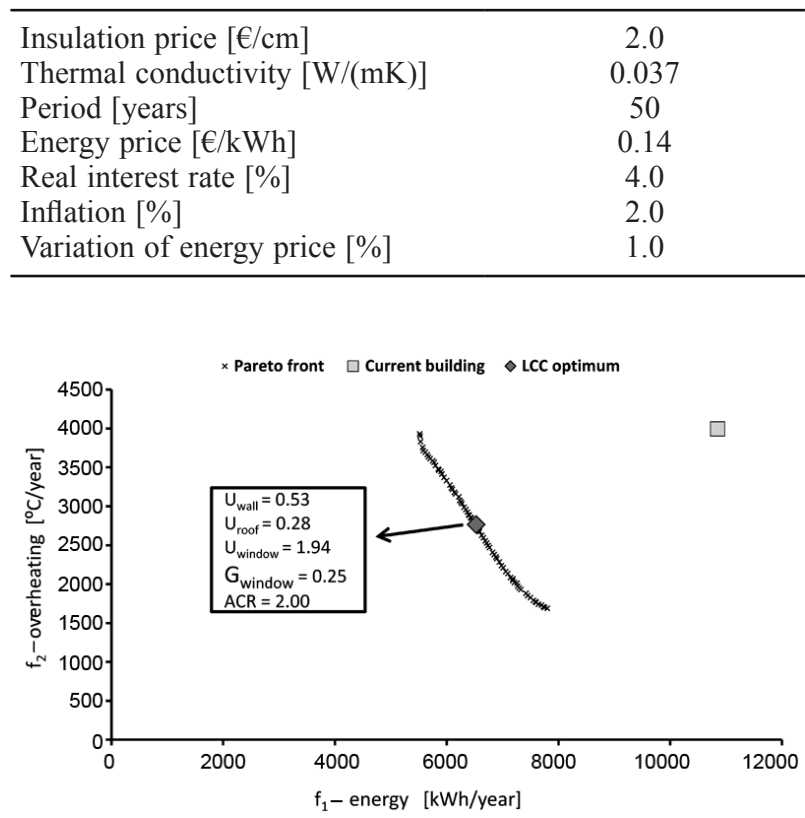

Fig. 7. Example case: output

of the methodology and of the software tool. An air change rate of $2.0 \mathrm{~h}^{-1}$ was considered. Table 4 includes the values considered for the investment and economic analysis inputs.

The software output is presented in Figure 7. Current building performance, Pareto front and LCC optimum are graphically represented. For the optimum solution the decision variables value are also indicated. It can be observed that the optimum solution corresponds to a situation near to maximum roof insulation $\left(\mathrm{U}_{\text {roof }}=0.28\right)$, since according to the decision space defined (Table 1) its minimum value is 0.25 .

From these results it is possible to calculate the optimum insulation thickness of external walls and roof. The software performs this task automatically. For this example, the optimum insulation thickness achieved by the LCC minimization was $3.9 \mathrm{~cm}$ and $10.9 \mathrm{~cm}$ for walls and roof, respectively.

\section{Conclusions}

An insulation thickness optimization methodology for school buildings rehabilitation combining artificial neural networks and life cycle cost was proposed. To this end five decision variables were defined and two mathematical functions were created to evaluate the building performance, one related to the heating energy demand and the other with the classrooms thermal discomfort due to overheating.

Since the optimization procedure is based on evolutionary algorithms, which require a large number of computer simulations, approximation methods were employed. ANN was the choice. The ANN proved to be effective and useful to approximate complex functions and, after being properly trained, can be used to 
replace the annual computer simulations. In this study, 96 ANN were created and validated with 10 cases. For the validation the respective $R^{2}$ was computed. The mean values obtained were $R^{2}=0.9818$ and $R^{2}=$ 0.9892 , for models A and B, respectively. Still, it was verified that ANN require a large number of input data for their training, in order to achieve a good approximation. For each, 160 cases were used, 150 for training and 10 for validation.

As expected, the optimization procedure revealed that Pareto fronts, i.e. the set of optimal solutions, are highly dependent on the minimum and maximum limits imposed for the variables space. In this particular case it was found that this is particularly important for the minimum limit of the air change rate.

The interpretation of Pareto fronts and subsequent definition of a criterion for the selection of a single solution is very complicated when dealing with problems such as the one presented. In this paper the inclusion of LCC as a decision criterion was proposed. For each solution belonging to the Pareto front the respective LCC was computed. The minimum LCC value was the decision criterion. This procedure allow the posterior calculation of the optimum insulation thickness of walls and roof. With this methodology the economic impact of the rehabilitation was implicitly introduced in the optimization. The method revealed that the LCC is a simple and appropriate instrument for this kind of problems.

The implementation was accomplished by the development of a software tool that automatizes the procedure. An example case of a typical Portuguese school building is presented.

\section{References}

Almeida, R.; Freitas, V. P. 2010. Hygrothermal performance of Portuguese classrooms: measurement and computer simulation, in Proc. of the $1^{\text {st }}$ Central European Symposium on Building Physics (CESBP-2010), 13-15 September 2010, Cracow, Poland, 379-386.

Aydinalp, M.; Ismet Ugursal, V.; Fung, A. S. 2004. Modeling of the space and domestic hot-water heating energyconsumption in the residential sector using neural networks, Applied Energy 79(2): 159-178.

http://dx.doi.org/10.1016/j.apenergy.2003.12.006

Ben-Nakhi, A. E.; Mahmoud, M. A. 2004. Cooling load prediction for buildings using general regression neural networks, Energy Conversion and Management 45(13): 2127-2141.

http://dx.doi.org/10.1016/j.enconman.2003.10.009

Boithias, F.; El Mankibi, M.; Michel, P. 2012a. Generic multiobjective optimization method of indoor and envelope systems' control, University "Politehnica" of Bucharest Scientific Bulletin, Series C: Electrical Engineering 74(1): 57-66.

Boithias, F.; El Mankibi, M.; Michel, P. 2012b. Genetic algorithms based optimization of artificial neural network architecture for buildings' indoor discomfort and energy consumption prediction, Building Simulation 5(2): 95-106. http://dx.doi.org/10.1007/s12273-012-0059-6

Calise, F. 2010. Thermoeconomic analysis and optimization of high efficiency solar heating and cooling systems for dif- ferent Italian school buildings and climates, Energy and Buildings 42(7): 992-1003.

http://dx.doi.org/10.1016/j.enbuild.2010.01.011

Calise, F. 2012. High temperature solar heating and cooling systems for different Mediterranean climates: dynamic simulation and economic assessment, Applied Thermal Engineering 32: 108-124.

http://dx.doi.org/10.1016/j.applthermaleng.2011.08.037

Calise, F.; D'accadia, M. D.; Vanoli, L. 2011. Thermoeconomic optimization of solar heating and cooling systems, Energy Conversion and Management 52(2): 1562-1573. http://dx.doi.org/10.1016/j.enconman.2010.10.025

Catalina, T.; Virgone, J.; Blanco, E. 2008. Development and validation of regression models to predict monthly heating demand for residential buildings, Energy and Buildings 40(10): 1825-1832. http://dx.doi.org/10.1016/j.enbuild.2008.04.001

Chantrelle, F. P.; Lahmidi, H.; Keilholz, W.; Mankibi, M. E.; Michel, P. 2011. Development of a multicriteria tool for optimizing the renovation of buildings, Applied Energy 88(4): $1386-1394$.

http://dx.doi.org/10.1016/j.apenergy.2010.10.002

Communities, O. J. O. T. E. 2003. Directive 2002/91/EC of the European Parliament and of the Council of 16 December 2002 on the energy performance of buildings. Brussels, Belgium.

Communities, O. J. O. T. E. 2010. Directive 2010/31/EU of the European Parliament and of the Council of 19 May 2010 on the energy performance of buildings (recast). Brussels, Belgium.

Deb, K. 2001. Multi-objective optimization using evolutionary algorithms. England, Chicester: John Wiley \& Sons, Ltd. $497 \mathrm{p}$.

Dhar, A.; Reddy, T. A.; Claridge, D. E. 1998. Modeling hourly energy use in commercial buildings with Fourier series functional forms, Journal of Solar Energy Engineering 120(3): 217-223. http://dx.doi.org/10.1115/1.2888072

Diakaki, C.; Grigoroudis, E.; Kolokotsa, D. 2008. Towards a multi-objective optimization approach for improving energy efficiency in buildings, Energy and Buildings 40(9): 17471754. http://dx.doi.org/10.1016/j.enbuild.2008.03.002

Diakaki, C.; Grigoroudis, E.; Kabelis, N.; Kolokotsa, D.; Kalaitzakis, K.; Stavrakakis, G. 2010. A multi-objective decision model for the improvement of energy efficiency in buildings, Energy 35(12): 5483-5496. http://dx.doi.org/10.1016/j.energy.2010.05.012

Freire, R. Z.; Oliveira, G. H. C.; Mendes, N. 2008. Development of regression equations for predicting energy and hygrothermal performance of buildings, Energy and Buildings 40(5): 810-820. http://dx.doi.org/10.1016/j.enbuild.2007.05.014

Gossard, D.; Lartigue, B.; Thellier, F. 2013. Multi-objective optimization of a building envelope for thermal performance using genetic algorithms and artificial neural network, Energy and Buildings 67: 253-260. http://dx.doi.org/10.1016/j.enbuild.2013.08.026

Guedes, M. C.; Matias, L.; Santos, C. P. 2009. Thermal comfort criteria and building design: field work in Portugal, Renewable Energy 34(11): 2357-2361. http://dx.doi.org/10.1016/j.renene.2009.03.004

Gustafsson, S. I. 2000. Optimisation of insulation measures on existing buildings, Energy and Buildings 33(1): 49-55. http://dx.doi.org/10.1016/S0378-7788(00)00062-1

Hamdy, M.; Hasan, A.; Siren, K. 2013. A multi-stage optimization method for cost-optimal and nearly-zero-energy building solutions in line with the EPBD-recast 2010, Energy and Buildings 56: 189-203. http://dx.doi.org/10.1016/j.enbuild.2012.08.023 
Hasan, A.; Vuolle, M.; Sirén, K. 2008. Minimisation of life cycle cost of a detached house using combined simulation and optimisation, Building and Environment 43(12): 2022 2034. http://dx.doi.org/10.1016/j.buildenv.2007.12.003

Inc., M. 2006. Matlab Documentation. Neural Network Toolbox 6 User's Guide.

Kreider, X. A. W. 1991. Artificial neural network demonstration for automated generation of energy use predictors for commercial buildings, ASHRAE Transactions 97(2): 775-779.

Karatasou, S.; Santamouris, M.; Geros, V. 2006. Modeling and predicting building's energy use with artificial neural networks: methods and results, Energy and Buildings 38(8): 949-958. http://dx.doi.org/10.1016/j.enbuild.2005.11.005

Kawashima, M.; Dorgan, C. E.; Mitchell, J. 1995. Hourly thermal load prediction for the next 24 hours by ARIMA, EWMA, LR, and an ANN, ASHRAE Transactions 101(1): 186-200.

Konak, A.; Coit, D. W.; Smith, A. E. 2006. Multi-objective optimization using genetic algorithms: a tutorial, Reliability Engineering \& System Safety 91(9): 992-1007. http://dx.doi.org/10.1016/j.ress.2005.11.018

Kumar, R.; Aggarwal, R. K.; Sharma, J. D. 2013. Energy analysis of a building using artificial neural network: a review, Energy and Buildings 65(0): 352-358. http://dx.doi.org/10.1016/j.enbuild.2013.06.007

Kumbaroğlu, G.; Madlener, R. 2012. Evaluation of economically optimal retrofit investment options for energy savings in buildings, Energy and Buildings 49(0): 327-334. http://dx.doi.org/10.1016/j.enbuild.2012.02.022

Magnier, L.; Haghighat, F. 2010. Multiobjective optimization of building design using TRNSYS simulations, genetic algorithm, and artificial neural network, Building and Environment 45(3): 739-746. http://dx.doi.org/10.1016/j.buildenv.2009.08.016

Marler, R. T.; Arora, J. 2010. The weighted sum method for multi-objective optimization: new insights, Structural and Multidisciplinary Optimization 41(6): 853-862. http://dx.doi.org/10.1007/s00158-009-0460-7

Mateus, T.; Oliveira, A. C. 2009. Energy and economic analysis of an integrated solar absorption cooling and heating system in different building types and climates, Applied Energy 86(6): 949-957.

http://dx.doi.org/10.1016/j.apenergy.2008.09.005
Mechaqrane, A.; Zouak, M. 2004. A comparison of linear and neural network ARX models applied to a prediction of the indoor temperature of a building, Neural Computing \& Applications 13(1): 32-37. http://dx.doi.org/10.1007/s00521-004-0401-8

O’Neill, P. J.; Crawley, D. B.; Schliesing, J. S. 1991. Using regression equations to determine the relative importance of inputs to energy simulations tools, in Building Simulation'91, 20-22 August 1991, Sophia-Antipolis, Nice, France, 283-289.

Ochoa, C. E.; Aries, M. B. C.; Van Loenen, E. J.; Hensen, J. L. M. 2012. Considerations on design optimization criteria for windows providing low energy consumption and high visual comfort, Applied Energy 95: 238-245. http://dx.doi.org/10.1016/j.apenergy.2012.02.042

Ozel, M. 2012. Cost analysis for optimum thicknesses and environmental impacts of different insulation materials, Energy and Buildings 49: 552-559. http://dx.doi.org/10.1016/j.enbuild.2012.03.002

Ozel, M. 2013. Determination of optimum insulation thickness based on cooling transmission load for building walls in a hot climate, Energy Conversion and Management 66: $106-114$ http://dx.doi.org/10.1016/j.enconman.2012.10.002

Santamouris, M.; Mihalakakou, G.; Patargias, P.; Gaitani, N.; Sfakianaki, K.; Papaglastra, M., Pavlou, C.; Doukas, P.; Primikiri, E.; Geros, V. 2007. Using intelligent clustering techniques to classify the energy performance of school buildings, Energy and Buildings 39(1): 45-51. http://dx.doi.org/10.1016/j.enbuild.2006.04.018

Suga, K.; Kato, S.; Hiyama, K. 2010. Structural analysis of Pareto-optimal solution sets for multi-objective optimization: an application to outer window design problems using multiple objective genetic algorithms, Building and Environment 45(5): 1144-1152. http://dx.doi.org/10.1016/j.buildenv.2009.10.021

Tso, G. K. F.; Yau, K. K. W. 2007. Predicting electricity energy consumption: a comparison of regression analysis, decision tree and neural networks, Energy 32(9): 1761-1768. http://dx.doi.org/10.1016/j.energy.2006.11.010

Wright, J. A.; Loosemore, H. A.; Farmani, R. 2002. Optimization of building thermal design and control by multi-criterion genetic algorithm, Energy and Buildings 34(9): 959-972. http://dx.doi.org/10.1016/S0378-7788(02)00071-3

Ricardo M. S. F. ALMEIDA. He is an Assistant Professor of Civil Engineering in the School of Technology \& Management at the Polytechnic Institute of Viseu and a researcher in the Building Physics Laboratory at Faculty of Engineering of University of Porto, Portugal. His research interests include the hygrothermal performance, energy efficiency, and in situ testing of buildings or building components and the dynamic simulation of energy in buildings.

Vasco Peixoto DE FREITAS. He is a Full Professor of Civil Engineering in Faculty of Engineering of University of Porto, Portugal and the Director of the Building Physics Laboratory, since 1991. He is the Coordinator of CIB-W40 and Joint Coordinator of CIB-W86. His research interests include the hygrothermal performance, energy efficiency, in situ testing, pathology, durability, maintenance and rehabilitation of buildings or building components. 